\title{
Intravenous ATP infusions can be safely administered in the home setting: a study in pre-terminal cancer patients
}

\author{
Sandra Beijer • Eric A. R. Gielisse • \\ Pierre S. Hupperets • Ben E. E. M. van den Borne • \\ Marieke van den Beuken-van Everdingen • \\ Marten R. Nijziel • Arjen M. J. van Henten • \\ Pieter C. Dagnelie
}

Received: 11 June 2007 / Accepted: 31 July 2007 / Published online: 5 September 2007

(C) Springer Science + Business Media, LLC 2007

Summary The aim of the study was to investigate the
safety of adenosine 5 '-triphosphate (ATP) administration at
home in pre-terminal cancer patients. Included were
patients with cancer for whom medical treatment options
were restricted to supportive care, who had a life
expectancy of less than 6 months, a World Health
Organization performance status 1 or 2 , and suffered from
at least one of the following complaints: fatigue, anorexia

S. Beijer $(\bowtie) \cdot$ E. A. R. Gielisse $\cdot$ P. C. Dagnelie

Department of Epidemiology, NUTRIM, Maastricht University,

P.O. Box 616, 6200 MD Maastricht, The Netherlands

e-mail: sandra.beijer@epid.unimaas.nl

\section{P. S. Hupperets}

Department of Internal Medicine/Oncology,

University Hospital Maastricht,

P.O. Box 5800, 6202 AZ Maastricht, The Netherlands

B. E. E. M. van den Borne

Department of Pulmonology, Catharina Hospital Eindhoven,

P.O. Box 1350, 5602 ZA Eindhoven, The Netherlands

M. van den Beuken-van Everdingen

Pain Management and Research Center,

University Hospital Maastricht,

P.O. Box 5800, 6202 AZ Maastricht, The Netherlands

M. R. Nijziel

Department of Internal Medicine/Haemato-Oncology,

Maxima Medical Center,

P.O. Box 90052, 5600 PD Eindhoven, The Netherlands

\section{A. M. J. van Henten}

Department of Pulmonology,

Maxima Medical Center,

P.O. Box 90052, 5600 PD Eindhoven, The Netherlands or weight loss $>5 \%$ over the previous 6 months. Side effects were registered systematically on a standard form according to the National Cancer Institute (NCI) Common Toxicity Criteria. Fifty-one patients received a total of 266 intravenous ATP infusions. Of these, 11 infusions (4\%) were given at the lowest dose of $20 \mu \mathrm{g} \mathrm{kg}^{-1} \mathrm{~min}^{-1}, 85$ infusions (32\%) at 25-40 $\mathrm{g} \mathrm{kg} \mathrm{k}^{-1} \mathrm{~min}^{-1}$, and $170(64 \%)$ at the highest dose of $45-50 \mu \mathrm{g} \mathrm{kg}^{-1} \mathrm{~min}^{-1}$ ATP. The majority of ATP infusions (63\%) were without side effects. Dyspnea was the most common side effect (14\% of infusions), followed by chest discomfort (12\%) and the urge to take a deep breath (11\%). No symptoms of cardiac ischemia occurred in any of the infusions. All side effects were transient and resolved within minutes after lowering the ATP infusion rate. Side effects were most frequent in the presence of cardiac disorders. We conclude that ATP at a maximum dose of $50 \mu \mathrm{g} \mathrm{kg}^{-1} \mathrm{~min}^{-1}$ can be safely administered in the home setting in patients with pre-terminal cancer.

Keywords ATP · Side effects · Pre-terminal cancer . Home-infusion

\section{Introduction}

In recent years favorable effects of adenosine 5 '-triphosphate (ATP) on nutritional and functional status and survival in cancer patients were reported [1-5]. However, ATP [6-10] and its breakdown product adenosine [11-18], given either as a continuous intravenous infusion or by intravenous bolus administration, were also reported to have side effects, which might hamper administration especially in an outpatient setting. 
In cancer patients, ATP was administered as continuous intravenous infusions over several hours, in doses varying from 25 to $100 \mu \mathrm{g} \mathrm{kg}^{-1} \mathrm{~min}^{-1}$. In a Phase I study [4], 14 patients with advanced cancer received 96-h infusions of ATP once per month for a total of at least three infusions, as tolerated by the patient. In the first three patients, ATP was given at a dose of $50 \mu \mathrm{g} \mathrm{kg}{ }^{-1} \mathrm{~min}^{-1}$. If well tolerated, subsequent dose escalations were planned in groups of three patients in increments of $25 \mu \mathrm{g} \mathrm{kg}^{-1} \mathrm{~min}^{-1}$ until the maximally tolerated dose (MTD) was reached. Patients who completed therapy without serious toxicity and later progressed were eligible for retreatment at a higher dose of ATP. Fourteen patients received a total of 43 ATP infusions: 11 patients received 29 infusions at a dose of $50 \mu \mathrm{g} \mathrm{kg}^{-1} \mathrm{~min}^{-1}$, six patients received 11 ATP infusions at a dose of $75 \mu \mathrm{g} \mathrm{kg}^{-1} \mathrm{~min}^{-1}$, and three patients who had tolerated $50 \mu \mathrm{g} \mathrm{kg}^{-1} \mathrm{~min}^{-1}$ very well were reconsented and received one cycle each at a dose of $100 \mu \mathrm{g} \mathrm{kg}^{-1} \mathrm{~min}^{-1}$. In total, 179 adverse events were reported, whether or not these could be ascribed to ATP. The majority of side effects (dyspnea, chest pain, hypotension, gastrointestinal side effects, dizziness, headache, fever and local injection site reaction) were minor (104 adverse events grade 1 $(58 \%)$ and 54 adverse events grade $2(30 \%)$ based on the US National Cancer Institute Toxicology Criteria. Doselimiting toxicities of ATP were reported in seven patients, i.e. asymptomatic electrocardiographic evidence of cardiac ischemia $(n=2)$, grade 3 cardiac toxicity (angina without evidence of infarction), and grade 4 pulmonary toxicity (dyspnea at rest), usually occurring as a characteristic cardiopulmonary syndrome including an initial feeling of chest 'tightness' and a sensation of 'needing to take a deep breath' $(n=5)$. Dose-limiting cardiopulmonary toxicity appeared in all three $100 \mu \mathrm{g} \mathrm{kg}^{-1} \mathrm{~min}^{-1}$ ATP infusions, in four (36\%) $75 \mu \mathrm{g} \mathrm{kg}^{-1} \mathrm{~min}^{-1}$ infusions, and in five (17\%) $50 \mu \mathrm{g} \mathrm{kg}^{-1} \mathrm{~min}^{-1}$ infusions.

In a subsequent uncontrolled phase II study [5], 15 previously untreated patients with stage IIIB/IV non-smallcell lung cancer (NSCLC) received infusions of ATP at doses of 50 (first course) and $65 \mu \mathrm{g} \mathrm{kg}^{-1} \mathrm{~min}^{-1}$ (subsequent courses) for $96 \mathrm{~h}$ every 4 weeks. Reported side effects were, in decreasing frequency, chest pain, dyspnea, coughing, anxiety, injection site pain, chest tightness, headache, insomnia, and hot flushes. According to the authors, six patients reported severe adverse events, of which CTC 4 dyspnea occurred in two patients; this led to the cessation of treatment in five patients [5].

In the first randomized clinical trial with ATP [1], 28 patients with stage IIIB/IV NSCLC received a total of 176 intravenous ATP courses, at doses of maximally $75 \mu \mathrm{g} \mathrm{kg}^{-1}$ $\mathrm{min}^{-1}$ (tailored to the maximum tolerance of each patient) for $30 \mathrm{~h}$ every 2-4 weeks. Twenty-nine percent of the infusions were given at rates of $25-40 \mu \mathrm{g} \mathrm{kg}^{-1} \mathrm{~min}^{-1}, 27 \%$ at $45-$
$60 \mu \mathrm{g} \mathrm{kg}^{-1} \mathrm{~min}^{-1}$ and $44 \%$ at $65-75 \mu \mathrm{g} \mathrm{kg}^{-1} \min ^{-1}$ [19]. The most frequent side effects were chest discomfort $(15 \%)$ and the urge to take a deep breath $(10 \%)$, both of which resolved within minutes after lowering the ATP dose. Electrocardiography (ECG) was performed in patients with chest pain/discomfort during the ATP infusions, but no ECG changes suggestive of myocardial ischemia were detected [19]. In all of the above studies, ATP was administered on an inpatient basis under medical supervision.

Based on the previously reported favorable effects of ATP on quality of life, nutritional status and survival [1,3], we initiated a new randomized clinical trial to investigate whether these effects of ATP could be confirmed in patients with different types of cancer in the pre-terminal stage of disease (life expectancy 1-6 months). In view of the short life expectancy of these patients, and based on the favorable safety profile of ATP, we decided to administer ATP in the home setting.

The aim of the present study was to investigate the safety of ATP administration at home in pre-terminal cancer patients. We hypothesized that side effects of ATP infusions would occur mainly during the first ATP infusion, especially during assessment of the MTD of ATP. We also hypothesized that the presence of cardiac disorders and/or lung cancer would lead to a lower MTD, and a higher frequency of side effects.

\section{Patients and methods}

\section{Study population and design}

Patients were recruited through the Departments of Medical Oncology and Pulmonology of five hospitals in different regions in The Netherlands (Maastricht, Eindhoven, Utrecht and Heerlen) and through general practitioners in the region of Maastricht. Eligible were patients with cytologically or histologically confirmed cancer, for whom medical treatment options were restricted to supportive care, who had a life expectancy $<6$ months, had a World Health Organization (WHO) performance status 1 or 2, and who at the time of inclusion suffered from at least one of the following complaints: fatigue, anorexia, or weight loss $>5 \%$ in the previous 6 months. Exclusion criteria were: symptomatic angina pectoris, symptomatic heart failure, atrio-ventricular block (checked by standard ECG in all patients before inclusion), life expectancy of less than 4 weeks, concurrent palliative chemotherapy at the time of inclusion, cognitive dysfunction, and the presence of other diseases hampering adequate follow up. The eligibility of patients was evaluated by a medical oncologist or pulmonologist. After baseline measurements, patients were randomly allocated to 
ATP or control treatment. The present report on the safety of ATP administration is restricted to patients randomized to ATP treatment. The study was approved by the Ethical Committee of University Hospital Maastricht and Maastricht University, and all patients signed written informed consent prior to the study. Details of the trial design have been published elsewhere [20].

\section{Intervention}

Adenosine 5 -triphosphate (ATP- $\mathrm{Na}_{2}$ ) of $>98 \%$ purity was purchased from Pharma Waldhof $\mathrm{GmbH}$ and co. KG (Düsseldorf, Germany). For each infusion, $2.5 \mathrm{~g}$ of ATP were dissolved in $500 \mathrm{ml} \mathrm{NaCl} 0.9 \%$, sterilized by ultrafiltration (Minisart $0.22 \mu \mathrm{M}$ ), and supplied in sterile containers. Patients received weekly intravenous ATP infusions of $8-12 \mathrm{~h}$, over a period of 8 weeks. All ATP infusions were started at a dose of $20 \mu \mathrm{g} \mathrm{kg}^{-1} \mathrm{~min}^{-1}$ and then increased in steps of $10 \mu \mathrm{g} \mathrm{kg}^{-1} \mathrm{~min}^{-1}$ every $10 \mathrm{~min}$, until a maximum dose of $50 \mu \mathrm{g} \mathrm{kg}^{-1} \mathrm{~min}^{-1}$, or the MTD, if this was lower, had been reached. Thereafter, ATP was infused at a continuous rate. If any side effects occurred, the dose was reduced until side effects disappeared. Blood pressure and pulse were registered before starting the infusion, at $30 \mathrm{~min}$ after determining the MTD, and just before the infusion was stopped.

Since initiation of ATP infusions under medical supervision in a clinical setting would facilitate the treatment of possible side effects, the first two ATP infusions were given at the day care center of the participating hospitals. Based on evaluation of safety data in the first 22 patients, in view of the mild character of the noted side effects during the first two infusions in these patients, the Ethical Committee granted permission to administer only the first ATP infusion at the day care center and all subsequent infusions at home. The description below applies to the procedures in case of only one hospital infusion.

At the end of the first infusion, the safety and tolerated dose of ATP was evaluated for each individual patient. Subsequent infusions were given at the patients' home by an experienced and trained nurse of a specialized infusion team, usually embedded in the regional Community Care Organization. The MTD as determined during the first infusion at the day care center was also the maximum dose for this patient for the next infusions at home. The same rule was applied for subsequent home infusions, so that the infusion rate in any subsequent ATP infusion course was never higher than the MTD during the previous ATP infusion. Patients and their partners were instructed extensively regarding the infusion procedures; also, they were instructed to immediately call the involved infusion team in case of any side effects.
Documentation of side effects and adverse events

\section{Side effects of ATP infusions}

Side effects of all ATP infusions, adjustments of dosage schedules, and any other events occurring during the infusions were registered by the infusion nurse, either a. during the infusions, or b. on completion of each infusion. In addition, the researcher called all patients after each infusion to ask whether any side effects had occurred. Side effects were scored using the NCI Common Toxicity Criteria [21] on a four-point scale, according to seriousness. In this system, dyspnea is graded as follows: 0 , no change; 1 , not defined; 2 , dyspnea on significant exertion; 3, dyspnea at normal activity; 4, dyspnea at rest. Since most terminal cancer patients are at rest, dyspnea would in these cases automatically be classified as CTC grade 4, which would misrepresent the actual severity of the symptoms and disregard the intention of the NCI Common Toxicity Criteria (i.e. CTC grade $4=$ life-threatening). For this reason, we decided to apply the general toxicity grading of the CTC also for dyspnea, i.e. 1, mild; 2, moderate; 3 , severe; and 4, life-threatening.

Based on Agteresch et al. [19], we pre-defined 13 side effects: chest discomfort, urge to take a deep breath, nausea, flushing, light-headedness, dyspnea, headache, sweating, mood alteration-anxiety, palpitations, epistaxis, symptoms of cardiac ischemia, injection side reaction or other (to be specified). In case of persistent or severe chest pain, suspect for potential cardiac ischemia, an ECG was made in order to exclude this.

\section{Statistical analysis}

Data were entered in a database using Microsoft Access 2000 and checked for errors by means of double data entry by two independent persons. Data were analyzed using SPSS 13.0 for Windows. Changes in blood pressure and heart rate over time were tested for statistical significance by Student's paired $t$ test. To test our hypothesis that side effects would especially occur during the first infusion, we calculated the average number of side effects per infusion over all infusions. To investigate whether the MTD and frequency of side effects were dependent on the presence of cardiac disorders and/or lung cancer, linear regression models were fitted. As dependent variables, we used mean MTD per patient over all courses, and frequency of side effects per infusion. As independent variables, we included dummy variables for the presence of cardiac disorders (yes/ no), and lung cancer (yes/no).To investigate the relation between the seriousness of side effects (CTC grades 2-4 vs. CTC grade 1) and the presence of cardiac disorders and/or lung cancer, Fisher's exact test was used. $P$ values of less than 0.05 indicated significance. 


\section{Results}

Study population

Fifty-one patients with different types of pre-terminal cancer were included in the present study. Baseline characteristics of the patients are listed in Table 1. Mean age was 68.1 years (range: 45-87 years) and the majority of patients were male $(69 \%)$. The most frequent diagnosis was lung cancer $(41 \%)$, followed by colon cancer (16\%). The majority of patients $(65 \%)$ had WHO performance status 1, and 35\% WHO status 2. Twelve patients $(24 \%)$ suffered from cardiac disorders.

Out of 51 patients, six patients died during the intervention period because of disease progression (Fig. 1). Three patients did not start because of rapid deterioration of their condition and 18 patients stopped with the ATP infusions. Reasons to stop were deterioration in medical condition $(n=11)$, fear of side effects $(n=4)$, or being unsatisfied with the effect of ATP $(n=3)$.

Over the study period of 8 weeks, a total of 266 ATP infusions were administered in 48 patients. Fifteen patients (31\%) received one to three ATP courses, nine patients $(19 \%)$ received four to seven courses, and 24 patients $(50 \%)$ completed all eight ATP infusions. Eleven infusions (4\%) of 266 infusions were given at the lowest dose of $20 \mu \mathrm{g} \mathrm{kg}$ $\min ^{-1}, 85$ infusions $(32 \%)$ at a dose of $25-40 \mu \mathrm{g} \mathrm{kg}^{-1} \mathrm{~min}^{-1}$, and $170(64 \%)$ at the highest dose of $45-50 \mu \mathrm{g} \mathrm{kg}^{-1} \mathrm{~min}^{-1}$.

Heart rate and blood pressure

Heart rate decreased from $86 \pm 1$ (mean \pm SEM) at baseline to $83 \pm 1$ at $30 \mathrm{~min}$ after reaching the MTD $(p<0.001)$, and

Table 1 Baseline characteristics of ATP-treated patients $(n=51)$

\begin{tabular}{|c|c|c|}
\hline & Number & Percent $(\%)$ \\
\hline Age (years) & $68.1(45-87)^{\mathrm{a}}$ & \\
\hline \multicolumn{3}{|l|}{ Gender } \\
\hline Male & 35 & 69 \\
\hline Female & 16 & 31 \\
\hline \multicolumn{3}{|l|}{ WHO performance score ${ }^{\mathrm{b}}$} \\
\hline 1 & 33 & 65 \\
\hline 2 & 18 & 35 \\
\hline \multicolumn{3}{|l|}{ Tumor type } \\
\hline Lung & 21 & 41 \\
\hline Colon & 8 & 16 \\
\hline Gastro-intestinal other & 6 & 12 \\
\hline Prostate & 5 & 10 \\
\hline Other & 11 & 21 \\
\hline Presence of cardiac disorders & 12 & 24 \\
\hline
\end{tabular}

${ }^{\mathrm{a}}$ Mean (range)

${ }^{\mathrm{b}}$ WHO 1: restricted in physically strenuous activity but ambulatory and able to do light work; WHO 2: ambulatory (not more than $50 \%$ in bed) and capable of self-care but unable to carry out any work thereafter remained constant at $83 \pm 1$ beats/min, as measured at $8-10 \mathrm{~h}$ of ATP administration (comparison with baseline: $p<0.001$ ). Systolic blood pressure decreased from $126 \pm 1$ at baseline to $124 \pm 2$ at $30 \mathrm{~min}(p<0.001)$, but then increased to $133 \pm 2 \mathrm{~mm} \mathrm{Hg}$ at $8-10 \mathrm{~h}$ of ATP infusion (comparison with baseline: $p<0.001)$. Diastolic blood pressure also initially decreased from $75 \pm 1 \mathrm{mmHg}$ to $72 \pm 1 \mathrm{mmHg}(p<0.001)$, but then increased to $77 \pm 1 \mathrm{~mm} \mathrm{Hg}$ at $8-10 \mathrm{~h}$ of ATP infusion (comparison with baseline: $p=0.02$ ).

Side effects

Ten patients out of 48 had no side effects during any of the infusions. Out of 266 infusions, 167 infusions (63\%) were without any side effects. In 48 infusions (18\%) 1 side effect occurred, in 29 infusions (11\%) 2 side effects, and in 22 infusions $(8 \%)>2$ side effects. In total, 192 side effects were reported (Fig. 2): 138 side effects $(72 \%)$ were reported to the nurse, of which 96 during the infusions and 42 afterwards; and 54 (28\%) to the researcher when specifically asked for. The average number of side effects per infusion was 0.72 (i.e. 192 side effects in 266 infusions).

At the day care center, 63 side effects were reported in 95 infusions ( 0.66 side effect per infusion). Of these 63 side effects, 56 (89\%) were reported to the nurse, of which 55 during the infusions and 1 afterwards; and 7 (11\%) to the researcher when specifically asked for. At home, 129 side effects were reported in 171 infusions $(0.75$ side effect per infusion); of these, $82(64 \%)$ were reported to the nurse, of which 41 during the infusions and 41 afterwards; and 47 $(36 \%)$ to the researcher when specifically asked for. All side effects were transient and resolved within minutes after lowering the ATP infusion rate.

In a total of 99 infusions, one or more side effects were reported by patients. In the 51 infusions with one or more side effects reported during ATP administration, the infusion was stopped in 13 infusions (25\%), lowered in 30 infusions $(59 \%)$ and not changed in 8 infusions $(16 \%)$. Of the latter eight infusions, the side effects had already disappeared before lowering the infusion rate in four infusions, whereas in three infusions the side effects had already been present before the start of the ATP infusions; in one infusion, extravasation occurred, and the ATP infusion was temporarily interrupted. In 48 out of the total of 99 infusions with one or more side effects, the side effects were reported by patients to the nurse or researcher only after completion of the infusion, and the infusion rate was therefore not adapted.

The frequency of specific side effects observed during the ATP infusions is shown in Table 2. Dyspnea was the most frequent side effect, appearing in 36 out of 266 infusions (14\%), followed by chest discomfort (12\%) and 
Fig. 1 Flow diagram of the study
Number of infusions

0

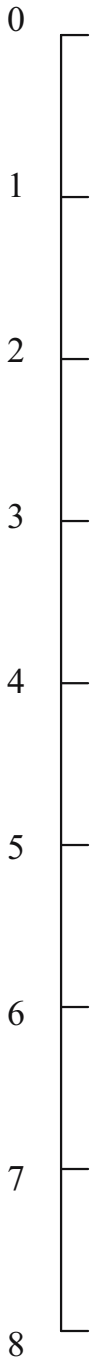

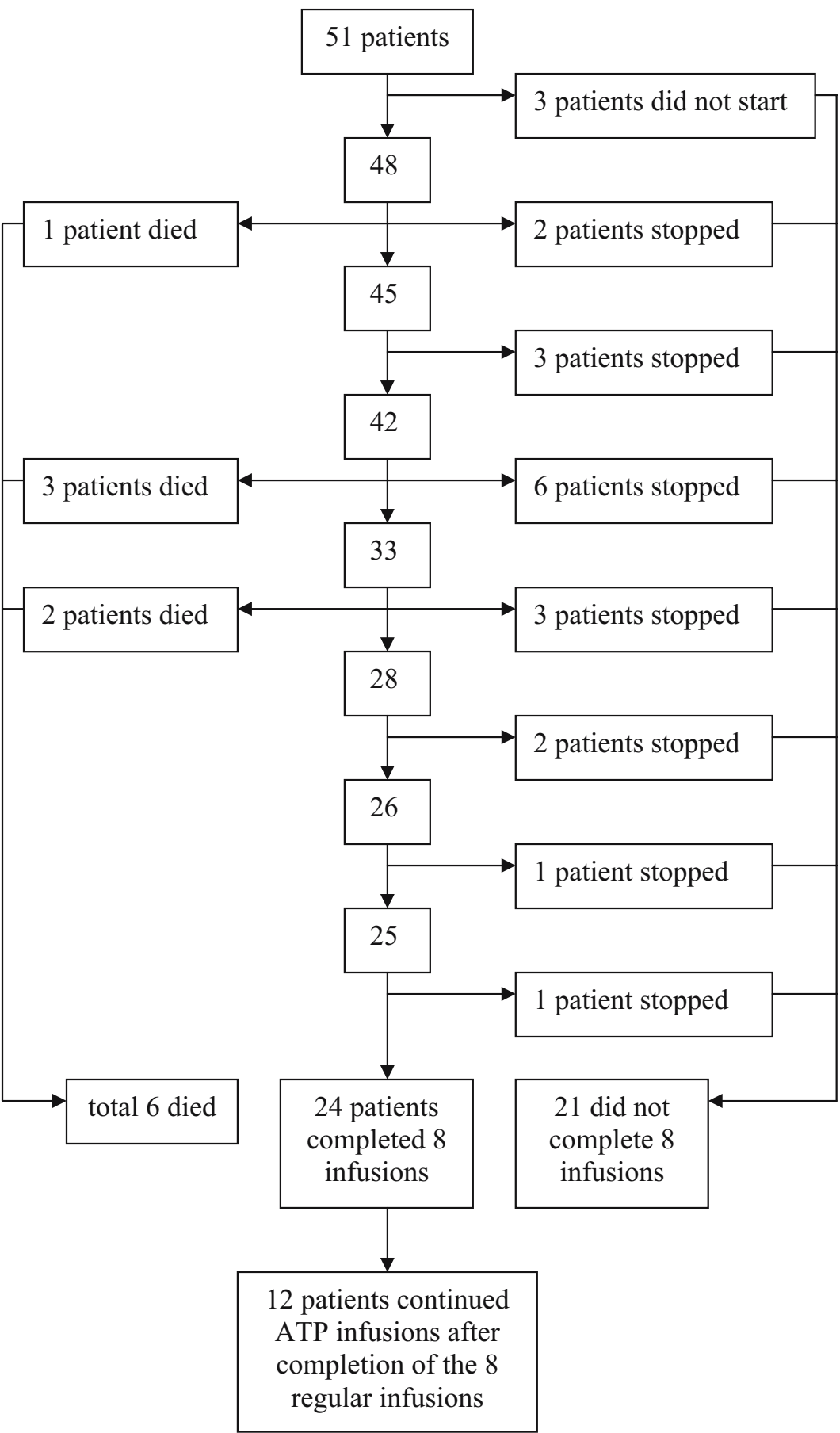

the urge to take a deep breath (11\%). No symptoms of cardiac ischemia occurred in any of the infusions.

From the 192 side effects, one side effect (lightheadedness) occurred at the day care center and was scored by the nurse as CTC 4 because of prolonged stay (one night) at the hospital after the first infusion; there were no abnormalities on ECG. Four side effects were scored as CTC 3 (in all cases chest discomfort), and 22 side effects as CTC 2 . Two CTC 3 side effects occurred at the day care center in two patients, with no abnormalities on ECG. Of these, one patient decided to stop with the ATP infusions. The other patient wanted to continue; for safety reasons, all subsequent infusions in this patient were given at the day care center. The remaining two CTC 3 side effects occurred at home: one in a patient during the normal procedure of stepwise increasing the infusion rate by the nurse according to protocol, in the other patient during constant ATP infusion after the nurse had left; in the latter case, the nurse was called by telephone by the patient or 
Fig. 2 Reported side effects of ATP according to location (day care centre vs. home), time of reporting side effects (during vs. after the infusion), and person to whom the side effects were reported (nurse vs. researcher)

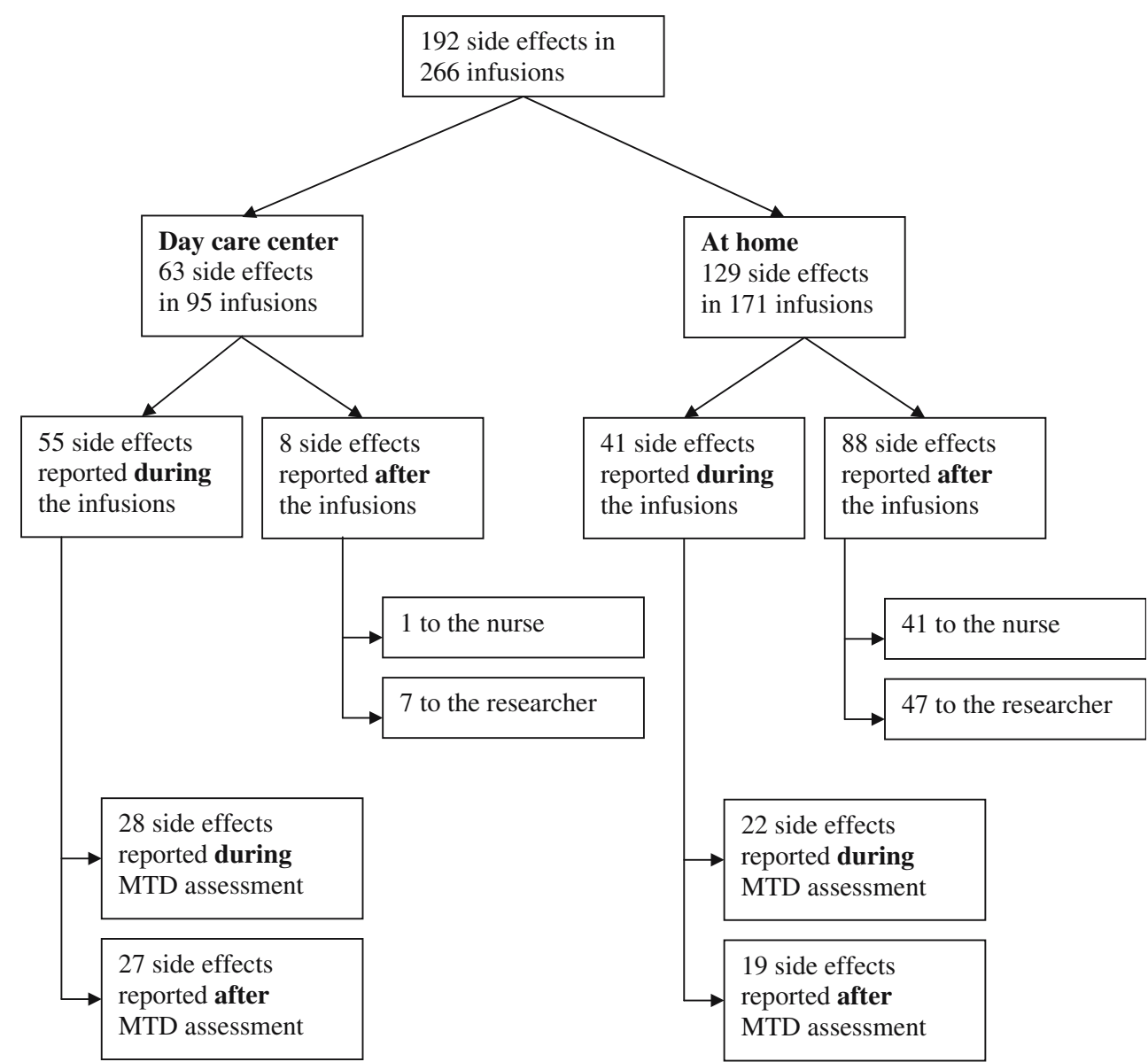

informal caregiver and immediately arrived. In both cases, the infusions were stopped immediately for that very day. The first patient decided to continue the ATP infusions; in this patient, all four subsequent infusions until the end of the study were given at the day care center at the highest ATP dose $\left(50 \mu \mathrm{g} \mathrm{kg}{ }^{-1} \mathrm{~min}^{-1}\right)$, and no further side effects occurred. The second patient decided to stop the ATP infusions.
Table 2 Side effects during a total of 266 intravenous ATP cycles in 51 patients;

CTC-grading
In some courses more than one side effect was observed

${ }^{\text {a }}$ The side effects classified as 'Other' were cold shivering, feelings of coldness, pain in infusion arm, dry eyes, sleepiness, burning sensation of the throat, vomiting, diarrhea, pain neck, general discomfort and unspecified

\begin{tabular}{|c|c|c|c|c|c|c|c|c|}
\hline \multirow[t]{2}{*}{ No side effects } & & \multicolumn{5}{|c|}{ Side effects according to CTC grade } & \multicolumn{2}{|c|}{ Total side effects } \\
\hline & & 1 & 2 & 3 & 4 & $\begin{array}{l}\text { CTC grade } \\
\text { unspecified }\end{array}$ & Number & $\begin{array}{l}\text { Percent of } \\
\text { inf. }(\%)\end{array}$ \\
\hline Cardiac ischemia & 266 & 0 & 0 & 0 & 0 & 0 & 0 & 0 \\
\hline Chest discomfort & 234 & 26 & 1 & 4 & 0 & 1 & 32 & 12 \\
\hline Dyspnea & 230 & 35 & 1 & 0 & 0 & 0 & 36 & 14 \\
\hline Epistaxis & 266 & 0 & 0 & 0 & 0 & 0 & 0 & 0 \\
\hline Flushing & 258 & 8 & 0 & 0 & 0 & 0 & 8 & 3 \\
\hline Headache & 252 & 11 & 2 & 0 & 0 & 1 & 14 & 5 \\
\hline Injection side reaction & 261 & 5 & 0 & 0 & 0 & 0 & 5 & 2 \\
\hline Lightheadedness & 254 & 9 & 2 & 0 & 1 & 0 & 12 & 5 \\
\hline Mood alteration-anxiety & 262 & 4 & 0 & 0 & 0 & 0 & 4 & 2 \\
\hline Nausea & 251 & 14 & 1 & 0 & 0 & 0 & 15 & 6 \\
\hline Other $^{\mathrm{a}}$ & 235 & 28 & 2 & 0 & 0 & 1 & 31 & 12 \\
\hline Palpitations & 265 & 1 & 0 & 0 & 0 & 0 & 1 & 0 \\
\hline Sweating & 260 & 2 & 3 & 0 & 0 & 1 & 6 & 2 \\
\hline Urge to take a deep breath & 238 & 18 & 10 & 0 & 0 & 0 & 28 & 11 \\
\hline Total & & 161 & 22 & 4 & 1 & 4 & 192 & \\
\hline
\end{tabular}


The following CTC 2 side effects were reported by patients:

1. To the nurse during the infusions, by seven patients in seven infusions:

- Urge to breathe deeply, headache, sweating and cold shivering in one patient at the day care center (the same patient with the CTC 3 chest discomfort and CTC 4 lightheadedness)

- Sweating in one patient at the day care center at the end of the infusion, due to flushing the infusion line (violation of the administration protocol)

- Pain in the infusion arm (one patient) and dyspnea (one patient), both at the day care center

- Urge to breathe deeply, headache and sweating in one patient at home, during the period of stepwise increasing the infusion rate by the nurse

- Chest discomfort (once) and lightheadedness (twice) at home in two patients, who called the home nurse

Out of these seven patients with CTC 2 side effects, two patients decided to stop the ATP infusions for the rest of the study.

2. To the nurse after completion of the infusion, by three patients (four infusions)

3. To the researcher when specifically asked for, by one patient (five infusions)

These nine CTC 2 side effects (eight times urge to breathe deeply, once nausea), were probably not sufficiently serious to call the home nurse. All of these patients continued the ATP infusions.

\section{Timing of side effects}

Side effects were not only present during the first infusion but also during subsequent infusions, even though the number of side effects per infusion appeared to be lower during the last three infusions (Fig. 3). At the day care center, of the 55 side

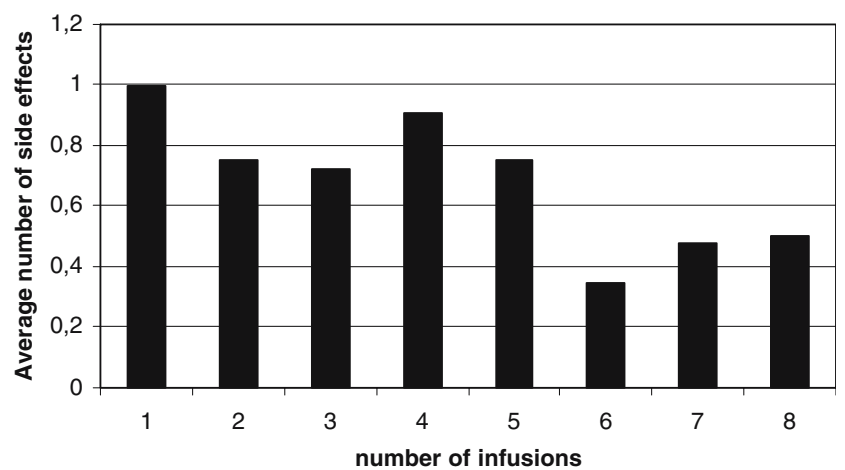

Fig. 3 Average number of side effects per ATP infusion in subsequent infusions effects reported during the infusions, 28 (51\%) were reported during MTD assessment and 27 side effects (49\%) after MTD assessment had been completed (Fig. 2). At home, 41 side effects were reported during the infusion, 22 side effects (54\%) during MTD assessment, and 19 side effects (46\%) after MTD assessment had been completed. In the latter 19 cases of side effects, the nurse (and once the general practitioner) was called by the patient and visited the patient to lower or stop the infusion rate.

Effect of cardiac or lung disorders on MTD and frequency of side effects

Mean MTD was $48 \pm 2($ mean $\pm \mathrm{SEM}) \mu \mathrm{g} \mathrm{kg}{ }^{-1} \min ^{-1}$ in patients without cardiac disorders and/or lung cancer (Table 3). In the presence of cardiac disorders mean MTD was $8 \mu \mathrm{g} \mathrm{kg}^{-1} \mathrm{~min}^{-1}$ lower $(p<0.001)$ and $4 \mu \mathrm{g} \mathrm{kg}^{-1} \mathrm{~min}^{-1}$ lower in the presence of lung cancer $(p=0.02)$. The mean number of side effects per infusion was $0.71 \pm 0.28$ in patients without cardiac disorders and/or lung cancer. In the presence of cardiac disorders, the number of side effects was significantly higher: $2.25 \pm 0.49(p=0.02)$. The presence of lung cancer had no significant impact on the frequency of side effects $(0.66 \pm 0.34)$. Neither the presence of cardiac disorders, nor the presence of lung cancer had a significant impact on the frequency of specific complaints (chest discomfort, urge to breathe deeply, nausea, lightheadedness, or dyspnea). However, in the presence of cardiac disorders, the number of other side effects was significantly higher $(p=$ 0.006). The proportion of CTC grade $2-4$ side effects in the presence of cardiac disorders and/or lung cancer (21 CTC grades 2-4 out of 133 side effects, i.e. 16\%) was similar to patients without such disorders (seven CTC grades 2-4 out of 59 side effects, i.e. $12 \%$ ).

Table 3 The independent effect of the presence of cardiac disorders and/or lung cancer on MTD and frequency of side effects

\begin{tabular}{lllc}
\hline Mean & $\begin{array}{l}\text { No cardiac } \\
\text { disorders and/or } \\
\text { lung cancer }\end{array}$ & $\begin{array}{l}\text { Cardiac } \\
\text { disorders }\end{array}$ & Lung cancer \\
\hline MTD & $48 \pm 2$ & $40 \pm 3^{* * *}$ & $44 \pm 2^{*}$ \\
All side effects & $0.71 \pm 0.28$ & $2.25 \pm 0.49^{*}$ & $0.66 \pm 0.34$ \\
Chest discomfort & $0.14 \pm 0.05$ & $0.32 \pm 0.09$ & $0.12 \pm 0.06$ \\
Urge to breathe deeply & $0.08 \pm 0.05$ & $0.25 \pm 0.08$ & $0.09 \pm 0.05$ \\
Nausea & $0.06 \pm 0.04$ & $0.18 \pm 0.07$ & $0.03 \pm 0.05$ \\
Lightheadedness & $0.06 \pm 0.04$ & $0.14 \pm 0.08$ & $0.06 \pm 0.05$ \\
Dyspnea & $0.12 \pm 0.05$ & $0.35 \pm 0.09$ & $0.17 \pm 0.06$ \\
Other & $0.09 \pm 0.06$ & $0.42 \pm 0.11^{* *}$ & $0.05 \pm 0.07$ \\
\hline
\end{tabular}

Reference group: patients with no cardiac disorders and/or lung cancer ${ }^{*} p<0.05$

$* * p<0.01$

$* * * p<0.001$ 
Continuation of infusions after completion of the study

Of the 24 patients who completed all eight ATP infusions, 12 decided to continue ATP administration (nine patients with lung cancer, one with prostate cancer, one with a malignant melanoma, one with liver cancer). Until the censoring date, these patients had received a total of 116 ATP infusions after completion of the regular 8-week study period (range 1-34 additional infusions). Of these 116 infusions, 11 infusions (10\%) reached a dose of $\leq 20 \mu \mathrm{g}$ $\mathrm{kg}^{-1} \mathrm{~min}^{-1}, 72$ infusions (62\%) were given at a dose of $25-$ $40 \mu \mathrm{g} \mathrm{kg}^{-1} \mathrm{~min}^{-1}$, and $33(28 \%)$ reached a dose of 45 $50 \mu \mathrm{g} \mathrm{kg}^{-1} \mathrm{~min}^{-1}$ ATP. A total of 38 side effects were reported over 116 infusions ( 0.33 side effects per infusion), a number significantly lower $(p<0.001)$ than in the first 8 infusions in the same 12 patients.

\section{Discussion}

The aim of this study was to investigate whether ATP can be safely administered to patients with pre-terminal cancer in the home setting. A total of 266 infusions were administered for 8-12 h. Although statistically significant changes in blood pressure and heart rate were observed, these were minor and clinically irrelevant, corroborating earlier results [19]. In total, 192 side effects were reported during the 266 ATP infusions, i.e. an average of 0.72 side effects per infusion. Most side effects were mild and transient, presumably due to the short plasma half-life of ATP and adenosine $(0.6-1.5 \mathrm{~s})$ [22].

We saw more side effects than in a previous study in 28 lung cancer patients by Agteresch et al. [19]. These authors observed 91 side effects during a total of 176 ATP cycles of $30 \mathrm{~h}$ ( 0.52 side effects per infusion), even though these infusions were administered for a longer period of time ( $30 \mathrm{~h}$ vs $8-10 \mathrm{~h}$ in our study). One possible explanation of this discrepancy may be the different procedures of data collection in these two studies. For safety reasons, the safety procedure adopted in the present study was that the researcher contacted the patients after each home infusion to ask for side effects, specifically naming a number of the most common potential side effects (based on side effects listed by Agteresch et al. [19]. Our results clearly demonstrate that this procedure lead to a higher frequency of reported side effects in our study: out of a total number of 192 side effects, 54 side effects (28\%) were reported only afterwards to the researcher when specifically asked for. If these side effects (i.e. side effects which had not spontaneously been reported to the nurse during or after the infusion) are excluded, the frequency of the remaining side effects per infusion in the present study $(138 / 266 ; 0.52)$ is remarkably similar to the report by Agteresch et al. [19]
(91/176; 0.52), in which trained research nurses in a dedicated clinical research unit registered the side effects.

In both our study and the studies by Haskell et al. [4, 5] and Agteresch et al. [19], chest discomfort/pain, dyspnea and the urge to take a deep breath were frequent side effects.

Results showed that in 43 out of 51 infusions (84\%) with side effects reported during ATP administration, the infusion rate was lowered or stopped according to protocol. Reasons for not lowering the infusion rate in eight infusions were the fact that in four infusions complaints disappeared automatically; in three infusions the reported complaints were already present before the start of the infusion; and in one infusion extravasation occurred with a temporary interruption of the ATP infusion.

In 48 infusions with side effects, side effects had only been reported after completion of the concerned ATP infusion and the infusion rate was therefore not adapted. One potential explanation for this finding may be that patients were eager to receive ATP at the highest possible dose, as some patients expressed their worry that the potential effectiveness of ATP could fade in case of lowering the dose (similar to chemotherapy), despite our explicit explanation to patients prior to the study that there is currently no evidence that the efficacy of ATP would be better at higher ATP doses. Another possible explanation is that patients in our study population were used to experiencing far more serious complaints caused by progression of the disease and/or previous antitumor treatment.

One CTC 4 side effect, four CTC 3 side effects, and 22 CTC score 2 were observed. The CTC 4 side effect (see "Results"), and two CTC 3 side effects (chest discomfort) occurred at the day care center, with no abnormalities on ECG. The other two CTC 3 side effects occurred at home, one with the nurse still being present; and in the other case, the nurse immediately arrived.

Side effects were not limited to the period of MTD assessment, nor were they limited to the first ATP infusion. The implication of this finding is that alertness with regard to potential side effects of ATP administration is necessary during all subsequent ATP infusions, and not just during the first infusion or MTD assessment.

The lower MTD found in the presence of cardiac disorders or lung cancer indicates that patients with these disorders tolerate lower doses of ATP without side effects than patients without these disorders. Moreover, even at the lower MTD, side effects tend to be more frequent in the presence of cardiac disorders. Because all patients with presence of COPD also had cardiac disorders or lung cancer, this subgroup was not analyzed separately.

Based on our findings, we conclude that ATP administration at home is safe. First, the majority of infusions (63\%) are without side effects, and second, our results confirm a previous study in lung cancer patients [19] showing that side 
effects that do appear are mild and transient, resolving within minutes after lowering the ATP infusion rate. Nevertheless, it remains possible that some side effects could be prevented by encouraging patients to report any side effects without delay. This emphasizes the need for careful instruction and facilitating patients reporting and monitoring of side effects when ATP infusions are administered at home. As patients with cardiac disorders and lung cancer appear to have a lower MTD and more side effects, these patients should be monitored with special care.

Acknowledgements This study was supported as a part of the programme "Palliative Care in the Terminal Phase" of The Netherlands Organization for Health Research and Development (ZonMw), and by the 'Stichting Nationaal Fonds tegen Kanker' (Foundation National Fund against Cancer), The Netherlands. The authors would like to thank Nicole Wijckmans for assistance with measurements and logistics.

\section{References}

1. Agteresch HJ, Dagnelie PC, van Der Gaast A, Stijnen T, Wilson JH (2000) Randomized clinical trial of adenosine 5'-triphosphate in patients with advanced non-small-cell lung cancer. J Natl Cancer Inst 92(4):321-328

2. Agteresch HJ, Rietveld T, Kerkhofs LG, van den Berg JW, Wilson JH, Dagnelie PC (2002) Beneficial effects of adenosine triphosphate on nutritional status in advanced lung cancer patients: a randomized clinical trial. J Clin Oncol 20(2):371-378

3. Agteresch HJ, Burgers SA, van der Gaast A, Wilson JH, Dagnelie PC (2003) Randomized clinical trial of adenosine 5'-triphosphate on tumor growth and survival in advanced lung cancer patients. Anticancer Drugs 14(8):639-644

4. Haskell CM, Wong M, Williams A, Lee LY (1996) Phase I trial of extracellular adenosine 5 -triphosphate in patients with advanced cancer. Med Pediatr Oncol 27(3):165-173

5. Haskell CM, Mendoza E, Pisters KM, Fossella FV, Figlin RA (1998) Phase II study of intravenous adenosine 5'-triphosphate in patients with previously untreated stage IIIB and stage IV nonsmall cell lung cancer. Invest New Drugs 16(1):81-85

6. Domanovits H, Laske H, Stark G, Sterz F, Schmidinger H, Schreiber W, Müllner M, Laggner AN (1994) Adenosine for the management of patients with tachycardias - a new protocol. Eur Heart J 15(5):589-593

7. Rankin AC, Oldroyd KG, Chong E, Dow JW, Rae AP, Cobbe SM (1990) Adenosine or adenosine triphosphate for supraventricular tachycardias? Comparative double-blind randomized study in patients with spontaneous or inducible arrhythmias. Am Heart $\mathbf{J}$ 119(2 Pt 1):316-323

8. Fukuda K, Hayashida M, Fukunaga A, Kasahara M, Koukita Y, Ichinohe T, Kaneko Y (2007) Pain-relieving effects of intravenous
ATP in chronic intractable orofacial pain: an open-label study. J Anesth 21(1):24-30

9. Komukai K, Hashimoto K, Shibata T, Iwano K, Muto M, Mogi J, Imai K, Horie T, Mochizuki S (2002) Effect of continuous ATP injection on human hemodynamics. Circ J 66(10):926-929

10. Gaba SJ, Prefaut C (1990) Comparison of pulmonary and systemic effects of adenosine triphosphate in chronic obstructive pulmonary disease-ATP: a pulmonary controlled vasoregulator? Eur Respir J 3(4):450-455

11. Holdgate A, Foo A (2006) Adenosine versus intravenous calcium channel antagonists for the treatment of supraventricular tachycardia in adults. Cochrane Database Syst Rev CD005154, (4)

12. Rankin AC, Oldroyd KG, Chong E, Rae AP, Cobbe SM (1989) Value and limitations of adenosine in the diagnosis and treatment of narrow and broad complex tachycardias. Br Heart J 62(3):195-203

13. DiMarco JP, Miles W, Akhtar M, Milstein S, Sharma AD, Platia E, McGovern B, Scheinman MM, Govier WC (1990) Adenosine for paroxysmal supraventricular tachycardia: dose ranging and comparison with verapamil. Assessment in placebo-controlled, multicenter trials. The Adenosine for PSVT Study Group [published erratum appears in Ann Intern Med 1990 Dec 15;113 (12):996]. Ann Intern Med 113(2):104-110

14. Sethi KK, Singh B, Kalra GS, Arora R, Khalilullah M (1994) Comparative clinical and electrophysiologic effects of adenosine and verapamil on termination of paroxysmal supraventricular tachycardia. Indian Heart J 46(3):141-144

15. Nesser HJ, Yao J, Soman P, Tkalec W, Ebner C, SteringerMascherbauer R, Markt B, Samenuk D, Ng CK, Morcerf F, Udelson JE, Pandian NG (2006) A head-to-head comparison of infusion and bolus doses of adenosine for stress myocardial contrast echocardiography. Echocardiography 23(6):483-489

16. Losek JD, Endom E, Dietrich A, Stewart G, Zempsky W, Smith K (1999) Adenosine and pediatric supraventricular tachycardia in the emergency department: multicenter study and review. Ann Emerg Med 33(2):185-191

17. Seet CM (1997) Efficacy of intravenous adenosine in treatment of paroxysmal supraventricular tachycardia in the local population. Singapore Med J 38(12):525-528

18. Verani MS, Mahmarian JJ, Hixson JB, Boyce TM, Staudacher RA (1990) Diagnosis of coronary artery disease by controlled coronary vasodilation with adenosine and thallium-201 scintigraphy in patients unable to exercise [see comments]. Circulation 82(1):80-87

19. Agteresch HJ, Dagnelie PC, Rietveld T, van den Berg JW, Danser AH, Wilson JH (2000) Pharmacokinetics of intravenous ATP in cancer patients. Eur J Clin Pharmacol 56(1):49-55

20. Beijer S, van Rossum E, Hupperets PS, Spreeuwenberg C, van den Beuken M, Winkens RA, Ars L, van den Borne BE, de Graeff A, Dagnelie PC (2007) Application of adenosine 5'-triphosphate (ATP) infusions in palliative home care: design of a randomized clinical trial. BMC Public Health 7:4

21. National Cancer Institute (1999) Common Toxicity Criteria, version 2.0. Publish National Cancer Institute, Bethesda, MD (April 30)

22. Moser GH, Schrader J, Deussen A (1989) Turnover of adenosine in plasma of human and dog blood. Am J Physiol 256(4 Pt 1): C799-C806 